(2) Open Access Full Text Article

\title{
Level of control among patients with type 2 diabetes mellitus attending diabetic clinic under family medicine compared to diabetic clinic under endocrinology
}

\author{
This article was published in the following Dove Press journal: \\ Diabetes, Metabolic Syndrome and Obesity:Targets and Therapy \\ 18 April 2016 \\ Number of times this article has been viewed
}

\author{
Mohammed A AlHabdan' \\ Mohammed A AlAteeq ${ }^{2}$ \\ Fiasal I AlJurbou' \\ 'College of Medicine, King Saud Bin \\ Abdul-Aziz University for Health \\ Sciences, ${ }^{2}$ Department of Family \\ Medicine and PHC, King Abdul-Aziz \\ Medical City, National Guard Health \\ Affairs, Riyadh, Kingdom of Saudi \\ Arabia
}

\begin{abstract}
Objectives: To assess and compare level of control among patients with type 2 diabetes mellitus attending diabetic clinic under family medicine service and patients attending diabetic clinics under endocrinology service, and to explore the effect of different variables on the level of control in both groups.
\end{abstract}

Methods: Retrospective cross-sectional study by reviewing medical records of patients with type 2 diabetes mellitus and laboratory studies from Hospital Information System at King Abdul-Aziz Medical City, National Guard, Riyadh - Saudi Arabia using predesigned sheet for data collection.

Results: Among 352 patients enrolled in the study, $176(50 \%)$ patients were from the family medicine setting and $176(50 \%)$ patients were from the hospital setting. The mean glycosylated hemoglobin for the whole study population was $8.97 \pm 1.87$. There was no significant difference between the two groups in regard to level of control $(9.01 \pm 1.75$ in the family medicine setting compared to $8.93 \pm 1.98$ in the hospital setting). No significant correlation was found between level of control and age, duration of disease and number of follow-up visits in both settings.

Conclusion: Patients with type 2 diabetes mellitus in this study were found to be poorly controlled in both the settings, diabetic clinic under family medicine and diabetic clinic under endocrinology. More research should be done to explore quality of care in a family medicine setting for patients with type 2 diabetes mellitus, as such a setting is expected to be more accessible, more convenient, and more cost effective to patients.

Keywords: DM, ambulatory care, family physicians, Saudi Arabia, National Guard

\section{Introduction}

Diabetes mellitus (DM) is considered as one of the common chronic diseases in the world nowadays. ${ }^{1}$ In 2011, there were more than 366 million people who had diabetes worldwide. $^{2}$ Type 2 diabetes represents $85 \%-95 \%$ of the total diabetes patients in the world, and without intervention, it is estimated that the number will increase up to 552 million in the year 2030. ${ }^{2}$ Bahrain, Kuwait, Lebanon, Oman, Saudi Arabia, and UAE are six of ten countries with the highest prevalence of diabetes in the world. ${ }^{2}$ According to a recent study, almost $30 \%$ of adult Saudi populations were found to have DM. ${ }^{3}$

There are different practices of DM management in Saudi Arabia, like other parts of the world, with a considerable variation between different locations. People with diabetes may be managed under general family medicine clinic, general internal medicine clinic, specialized diabetic clinics under different specialties with different
Correspondence: Mohammed A AIAteeq Department of Family Medicine and PHC, King Abdul-Aziz Medical City, National Guard Health Affairs, PO Box 22490, Riyadh I I426, Kingdom of Saudi Arabia Tel +966 I I80 I I I I Ext 46585 Email malateeq@hotmail.com
Diabetes, Metabolic Syndrome and Obesity:Targets and Therapy 2016:9 119-124

(c) (i) (5) 2016 Alltabdan et al. This work is published and licensed by Dove Medical Press Limited. The full terms of this license are available at https://www.dovepress.com/ (c) work you hereby accept the Terms. Non-commercial uses of the work are permitted without any further permission from Dove Medical Press Limited, provided the work is properly attributed. For permission for commercial use of this work, please see paragraphs 4.2 and 5 of our Terms (https://www.dovepress.com/terms.php). 
available resources and supportive services. This for sure will result in variable levels of care and control and need to be taken in to consideration in comparing results of different local studies.

In a study done in Albany, New York, adherence to American Diabetic Association clinical practice recommendations and lower levels of glycosylated hemoglobin (A1C) was found to be significantly better in the endocrinology clinic than in the primary care clinic. ${ }^{4}$ Another similar study done in Japan, found contradicting result where mean A1C level for patients treated by general practitioners was found significantly lower compared to patients treated by the diabetes specialists. $^{5}$

In 2006, a study was done in the US to evaluate the management of type 2 diabetes in the primary care setting and included 95 primary care clinicians and 822 patients with type 2 DM. The study showed that only modest number of patients achieve established targets of diabetes control. ${ }^{6}$

In the US, family practices employing nurse practitioners were found to perform better than those with physicians only and those employing physicians assistants, especially with regard to diabetes process measures. ${ }^{7}$ Another means of dramatic improvement in glycemic control is through community health care support systems, specifically psychological support. ${ }^{8}$ A local study, published in 2014, compared diabetes control among patients with type 2 DM managed in the primary health care clinics and patients managed at diabetes center at King Saud University Hospitals in Riyadh, Saudi Arabia. People with diabetes managed at primary care clinics were found to have better control in terms of A1C level. ${ }^{9}$

Another study published in the US in 1997 compared the quality of ambulatory diabetes care delivered by physicians in the diabetes clinic versus the general medicine clinic with 112 patients divided equally between both clinics. It showed that the proportion of patient visits meeting the minimally acceptable levels of quality was better in the diabetes clinic than the general medicine clinic and the diabetes clinic performed dramatically better than the general medicine clinic in regard to complete foot and examination, A1C measurement and diabetic education referral. ${ }^{10}$ Similar results were found in a meta-analysis of randomized trials comparing general practice and shared care with follow-up in a hospital outpatient clinic. ${ }^{11}$

Another study compared clinical performance for people with diabetes by traditional general practitioner clinics and diabetes clinics run by general practitioners with special interests. It found no evidence that patients in specialist clinics do better than patients in routine primary care clinics. ${ }^{12}$
The aim of this study was to assess and compare the level of control between patients attending diabetic clinic under family medicine and patients attending diabetic clinic under endocrinology, and to explore the effect of different variable on the level of control in both groups. The primary outcome to measure in this study was $\mathrm{A} 1 \mathrm{C}$ as recognized indicator for DM control.

\section{Materials and methods}

This was a chart review study done in the period from May 2013 to December 2014. The medical charts reviewed belonged to patients with type $2 \mathrm{DM}$ who were being followed in two centers: Diabetic Centre, King Abdul Aziz Housing Family Medicine Clinics, and Diabetic clinics, Ambulatory Care Center (ACC), King Abdul Aziz Medical City, National Guard, Riyadh, Saudi Arabia.

The Diabetic Centre at King Abdul Aziz Housing Family Medicine Clinics is a specialized center for the management and follow-up of patients with diabetes run by family medicine consultants. Diabetic clinics at the Ambulatory Care Center, King Abdul Aziz Medical City are specialized clinics for the management and follow-up of patients with diabetes run by endocrinologist. Both centers provided health care for patients with diabetes with multidisciplinary approach (diabetic educator, dietician, ophthalmologist, and podiatrist).

The inclusion criteria comprised adult patients with type 2 DM aged 20-65 years, seen at least once in the 6 months period prior to the study. The exclusion criteria comprised patients with type $1 \mathrm{DM}$, patients with diabetes due to secondary causes, patients with double follow-ups in both settings (diabetic center at family medicine clinic and diabetic clinics at ACC), pregnant female patients, patients aged younger than 20 years and older than 65 years.

We estimated the number of patients with type $2 \mathrm{DM}$ at King Abdul Aziz Housing Family Medicine Clinics, Riyadh to be 3,500 patients. By using sample size calculator with confidence level of $95 \%$, with a margin error $5 \%$, response distribution of $50 \%$, and population size of 3,500 patients with diabetes, the recommended sample size was 347 patients with diabetes. The sample size was increased to 352 to ensure data completeness. The medical chart was selected by choosing every other medical record number in the list of patients with diabetes booked in both settings.

Data was collected by reviewing patients' medical charts both paper copy file and e file using predesigned collecting sheet. The data collection sheet consists of three parts: part one for personal and demographic data (medical record 
number, nationality, age, sex, educational level), part 2 for DM data (duration of disease, comorbidities, and the clinic of follow-up), and part 3 for glycemic control data (last measured A1C, number of follow-up visits in the last 12 months, treatment type). The data collection sheet was designed after reviewing the published literature and based on the required information.

Data were entered and analyzed using Statistical Package for Social Sciences (SPSS) version 18 (IBM Corp., Chicago, IL, USA). The chi-square test was used to describe the association or difference between variables in different categories. All results were declared statistically significant with a $P$-value $<0.05$.

Ethical approval for patients' chart review was obtained from King Abdullah International Medical Research Center (KAIMRC) in Riyadh. The study was done in accordance with principles of the Declaration of Helsinki.

\section{Results}

Among 352 patients, 176 (50\%) patients were from family medicine clinics and $176(50 \%)$ patients were from endocrine clinics. In the family medicine clinics, 87 (49\%) patients were males and $89(51 \%)$ were females and in the endocrine clinics, 63 (36\%) were males and 113 (64\%) were females.

The mean age of patients in the family medicine clinics was $49.1 \pm 8.5$ years and $51.9 \pm 9.1$ years for patients in the endocrine clinic, with no significant difference between two groups.
There was significant difference in the duration of the disease between the two groups $(7.8 \pm 6.3$ years in the family medicine clinics patients and $10.8 \pm 7.3$ years in the endocrine clinics patients) with a $P$-value $<0.05$.

In comparing comorbidities, no significant difference for hypertension was found between family medicine patients and endocrine patients (57\% and 59\%, respectively) or stroke ( $1 \%$ in both groups). For hypothyroidism, there was a significant difference (10\% and $20 \%$, respectively) with a $P$-value $=0.005$, as well for dyslipidemia $(92 \%$ and $67 \%$, respectively) with $P$-value $<0.001$.

None of the patients in the family medicine clinics were treated with life style modifications alone, whereas $49 \%$ were treated with oral hypoglycemic agents (OHA), 5\% were treated with insulin alone, and $47 \%$ were treated with combined OHA and insulin. In the endocrine clinics, 5\% of the patients were treated with life style modifications alone, 38\% were treated with OHA, 29\% were treated with insulin alone, and $28 \%$ were treated with combined OHA and insulin (Table 1).

In regard to level of control, mean $\mathrm{A} 1 \mathrm{C}$ was found to be $8.97 \pm 1.87$ for all patients. It was $9.01 \pm 1.75$ for the family medicine clinics as compared to $8.93 \pm 1.98$ for the endocrine clinics, with no significant difference between two groups $(P$-value $=0.66)($ Table 2$)$.

When categorized into $<7,7-8,8-9,9-10$, and $>10$, A1C was found in the study population as follows: $12.5 \%, 21.6 \%$, $20.7 \%, 17.9 \%$, and $27.3 \%$, respectively. The percentage of

Table I Patients and disease characteristics $(n=352)$

\begin{tabular}{|c|c|c|c|c|}
\hline Patient characteristics & $\begin{array}{l}\text { Family medicine } \\
(\mathrm{N}=176)\end{array}$ & $\begin{array}{l}\text { Endocrine clinic } \\
(N=176)\end{array}$ & Total & $P$-value* \\
\hline Age, mean $\pm S D$ & $49.1 \pm 8.5$ & $51.9 \pm 9.1$ & $50.5 \pm 8.9$ & $0.002^{\mathrm{a}}$ \\
\hline \multicolumn{5}{|l|}{ Sex, n (\%) } \\
\hline Male & $87(49)$ & $63(36)$ & $150(43)$ & 0.01 \\
\hline Female & $89(5 I)$ & $113(64)$ & $202(57)$ & \\
\hline \multicolumn{5}{|l|}{ Type of treatment, n (\%) } \\
\hline Life style modification & $0(0)$ & $9(5)$ & $9(3)$ & \\
\hline Oral hypoglycemic & $86(49)$ & $67(38)$ & $153(43)$ & \\
\hline Insulin & $8(5)$ & $51(29)$ & $59(17)$ & \\
\hline Oral + insulin & $82(47)$ & $49(28)$ & $|3|(37)$ & \\
\hline \multicolumn{5}{|l|}{ Comorbidities, n (\%) } \\
\hline Hypertension & $100(57)$ & $104(59)$ & $204(58)$ & 0.67 \\
\hline Dyslipidemia & $162(92)$ & 118 (67) & $280(80)$ & $<0.001$ \\
\hline Stroke & $\mathrm{I}(\mathrm{I})$ & $\mathrm{I}(\mathrm{I})$ & $2(1)$ & 1.0 \\
\hline Hypothyroidism & $17(10)$ & $36(20)$ & $53(15)$ & 0.005 \\
\hline \multicolumn{5}{|l|}{ Duration of disease } \\
\hline Mean \pm SD & $7.8 \pm 6.3$ & $10.8 \pm 7.3$ & $9.3 \pm 7$ & $<0.00 \mathrm{I}^{\mathrm{a}}$ \\
\hline Median (IQR) & $6.0(3,11)$ & $10.0(5,15)$ & $8.0(4,14)$ & $<0.00 \mathrm{I}^{\mathrm{b}}$ \\
\hline
\end{tabular}

Notes: *P-value determined by chi-square test except for "age" and "duration of disease": andependent samples $t$-test. ${ }^{b} T e s t$ of median. $P$-value was considered significant if $<0.05$.

Abbreviations: IQR, interquartile range; SD, standard deviation. 
Table 2 Mean AIC in both groups

\begin{tabular}{llll}
\hline Clinic & N & Mean & P-value \\
\hline Both & 352 & $8.97 \pm 1.87$ & \\
Family medicine & 176 & $9.01 \pm 1.75$ & 0.66 \\
Endocrine clinic & 176 & $8.93 \pm 1.98$ & 0.66
\end{tabular}

Notes: The chi-square test was used to calculate $P$-value. $P$-value was considered significant if $<0.05$

Abbreviation: AIC, glycosylated hemoglobin.

well-controlled patients $(\mathrm{A} 1 \mathrm{C}<7)$ was found higher in endocrinology setting $(15.9 \%)$ than in family medicine setting (9.11\%) (Table 3). There was no difference for different categories of $\mathrm{A} 1 \mathrm{C}$ with regards to age (Table 4).

There was no significant correlation for A1C level with age, duration of disease, number of follow-up visits, and comorbidities in both settings (Tables 5 and 6).

\section{Discussion}

This study aimed to identify and compare the level of control of type 2 DM between two clinical settings: diabetic clinic under family medicine and diabetic clinic under endocrinology. The two groups of patients were matching for age, sex but not for the duration of the disease. Both clinical settings were following multidisciplinary approach with the availability of trained nurses, dieticians, health educators, podiatrists, and physicians at consultant level.

Current study found the mean A1C for all subjects at $8.97 \pm 1.87$, which indicate poor control with no significant difference between males and females. This finding is similar to other studies of type $2 \mathrm{DM}$ control in Saudi Arabia, which found the mean $\mathrm{A} 1 \mathrm{C}$ to be $8.5 \pm 1.51^{9}$ and $8.20 \pm 1.89 .{ }^{13}$

In the current study, more patients are well controlled in endocrinology than in family medicine setting, although the

Table 3 AIC categories for study population in both settings $(n=352)$

\begin{tabular}{|c|c|c|c|c|c|}
\hline & & & Clinic & & Total \\
\hline & & & $\begin{array}{l}\text { Family } \\
\text { medicine }\end{array}$ & $\begin{array}{l}\text { Endocrine } \\
\text { clinic }\end{array}$ & \\
\hline AIC & $<7$ & $\mathrm{~N}$ & 16 & 28 & 44 \\
\hline & & Within clinic, \% & 9.1 & 15.9 & 12.5 \\
\hline & 7 to $<8$ & $\mathrm{~N}$ & 38 & 38 & 76 \\
\hline & & Within clinic, \% & 21.6 & 21.6 & 21.6 \\
\hline & 8 to $<9$ & $\mathrm{~N}$ & 40 & 33 & 73 \\
\hline & & Within clinic, \% & 22.7 & 18.8 & 20.7 \\
\hline & 9 to $<10$ & $\mathrm{~N}$ & 38 & 25 & 63 \\
\hline & & Within clinic, \% & 21.6 & 14.2 & 17.9 \\
\hline & $\geq 10$ & $\mathrm{~N}$ & 44 & 52 & 96 \\
\hline & & Within clinic, \% & 25.0 & 29.5 & 27.3 \\
\hline Total, & $\mathrm{N}(\%)$ & & $176(100)$ & $176(100)$ & $352(100)$ \\
\hline
\end{tabular}

Abbreviation: AIC, glycosylated hemoglobin.
Table 4 Age distribution in relation to AIC categories $(n=352)$

\begin{tabular}{llll}
\hline Age & $\mathbf{N}$ & Mean of AIC & SD \\
\hline $26-39$ & 45 & 9.331 & 2.4692 \\
$40-49$ & 110 & 8.864 & 1.9419 \\
$50-59$ & 129 & 9.088 & 1.6734 \\
$60-69$ & 68 & 8.674 & 1.5861 \\
Total & 352 & 8.969 & 1.8652 \\
\hline
\end{tabular}

Abbreviations: AIC, glycosylated hemoglobin; SD, standard deviation.

overall percentage is low (12.5\%), which is really alarming and indicates the real need for more intensive management. It is much less than what was found internationally. For example, for European patients with type 2 DM, 37.4\% had A1C $\geq 7 \%$ in PANORAMA study, ${ }^{14}$ while only one-quarter had adequate glycemic control in the Alvarez et al ${ }^{15}$ study. One study done on senior Malaysian patients with type $2 \mathrm{DM}$, found that two-thirds of them had A1C $\geq 6.5 \% .{ }^{16}$ Another study that assessed the prevalence of good and inadequate glycemic control across a 5-year period among patients with diabetes in the UK found $>60 \%$ of patients had inadequate glycemic control (A1C $\geq 7 \%$ ). ${ }^{17}$ In another study done in Scotland, the overall control of patients with type $1 \mathrm{DM}$ was found to be poor with mean $\mathrm{A} 1 \mathrm{C}>9.1 \% .^{18}$

The difference in the level of control can be contributed to many factors. For example, a good number of patients with type $2 \mathrm{DM}$ are reluctant to start insulin treatment despite the clinical need, for different reasons. The issue of adherence to medication, underestimation of the disease by some patients, transportation difficulty for some female patients, all may be contributing factors.

In regard to the difference in DM control between the two settings, according to the current study, there was no significant difference between family medicine setting and endocrine setting. This result is contradicting results of other international studies. For example, a study conducted

Table 5 Correlation between AIC, age, duration of disease, and number of follow-up visits

\begin{tabular}{|c|c|c|c|c|}
\hline & & Age & $\begin{array}{l}\text { Duration } \\
\text { (years) }\end{array}$ & $\begin{array}{l}\text { Number of } \\
\text { follow-up } \\
\text { visits }\end{array}$ \\
\hline \multicolumn{5}{|c|}{ Family medicine clinic } \\
\hline \multirow[t]{3}{*}{ AIC } & Pearson correlation & 0.05 & 0.13 & -0.03 \\
\hline & Significant (two-tailed) & 0.53 & 0.08 & 0.66 \\
\hline & $\mathrm{N}$ & 176 & 176 & 176 \\
\hline \multicolumn{5}{|c|}{ Endocrine clinic } \\
\hline \multirow[t]{3}{*}{ AIC } & Pearson correlation & -0.16 & 0.24 & 0.13 \\
\hline & Significant (two-tailed) & 0.03 & 0.001 & 0.08 \\
\hline & $\mathrm{N}$ & 176 & 176 & 176 \\
\hline
\end{tabular}

Abbreviation: AIC, glycosylated hemoglobin. 
Table 6 Correlation between AIC and comorbidities

\begin{tabular}{|c|c|c|c|c|c|c|c|}
\hline & & \multicolumn{3}{|c|}{ Family clinic } & \multicolumn{3}{|c|}{ Endocrine clinic } \\
\hline & & $\mathbf{N}$ & Mean of AIC & $P$-value & $\mathbf{N}$ & Mean of HAlc & $P$-value \\
\hline \multirow[t]{2}{*}{ Hypertension } & Yes & 100 & $9.07 \pm 1.7$ & 0.60 & 104 & $8.83 \pm 1.9$ & 0.42 \\
\hline & No & 76 & $8.93 \pm 1.8$ & & 72 & $9.07 \pm 2.1$ & \\
\hline \multirow[t]{2}{*}{ Dyslipidemia } & Yes & 162 & $9.05 \pm 1.7$ & 0.34 & 118 & $8.94 \pm 2$ & 0.83 \\
\hline & No & 14 & $8.59 \pm 1.8$ & & 58 & $8.88 \pm 1.9$ & \\
\hline \multirow[t]{2}{*}{ Hypothyroidism } & Yes & 17 & $9.20 \pm 1.5$ & 0.63 & 36 & $9 \pm 2.1$ & 0.8 \\
\hline & No & 159 & $8.99 \pm 1.8$ & & 140 & $8.9 \pm 2$ & \\
\hline \multirow[t]{2}{*}{ Stroke } & Yes & 1 & 10.6 & 0.37 & I & 9.1 & 0.93 \\
\hline & No & 175 & $9 \pm 1.8$ & & 175 & $8.92 \pm 2$ & \\
\hline
\end{tabular}

Notes: Data presented as mean \pm standard deviation. The chi-square test was used to calculate $P$-value. $P$-value was considered significant if $<0.05$.

Abbreviation: AIC, glycosylated hemoglobin.

in Japan showed that the mean A1C level for all patients treated by general practitioners was significantly lower than for those treated by the diabetes specialists $(6.8 \% \pm 1.2 \%$ vs $7.0 \% \pm 1.2 \%, P=0.0002) .{ }^{8}$ Another three studies done in USA, found better control of patients with diabetes treated in the endocrinology clinic than in the primary care clinic. ${ }^{4,10,11}$ The different results in those studies compared to the current study may be related to different setting, wherein our study was a diabetic clinic under family medicine, while in the other three studies, it was a general practice setting.

For the level of control in the family medicine setting, the current study results are similar to the finding of another study done in US where only modest number of patients achieved established targets of diabetes control. ${ }^{6}$ A similar study done in US for patients with diabetes following-up in primary care clinics, $41.6 \%$ only achieved good control. ${ }^{19}$ A study, done in Riyadh, Saudi Arabia, found almost similar findings for the level of control of diabetes patients treated in primary care setting $(9.0 \% \pm 2.0 \%)$, although the management was conducted under general primary care clinics and not in specialized diabetic clinic. ${ }^{20}$

In our study, we found that patients with diabetes attending the endocrine clinic were predominantly female (64\%), which gives the possibility of endocrine medical conditions affecting females more commonly than males, such as hypothyroidism, which accounted for $20 \%$ of the chronic medical conditions in the population attending the endocrine clinic only.

The level of control in both clinics was found to be better with patients who are treated with $\mathrm{OHA}$ alone, while it was worse with the patients who are treated with OHA and insulin. This can be correlated to the stage and complexity of the disease in both groups.

In the current study, for patients in both settings, the age, duration of disease, number of follow-up visits, and comorbidities had shown no effects on patients' glycemic control. This may not reflect the actual association due to the limited study population size.

\section{Conclusion}

Patients with type 2 DM in this study were found to be poorly controlled in both settings, diabetic clinic under family medicine and diabetic clinic under endocrinology.

\section{Limitations}

This study was limited to explore the level of control as reflected by $\mathrm{A} 1 \mathrm{C}$ level. There was no exploration of detailed aspects of DM management in either the processes or other outcomes.

In addition, this study did not investigate the level of adherence to guidelines in management of DM in both settings. This may be an influencing factor affecting the level of control. Being retrospective, current study may be liable to selection bias, which was done in one health care facility. Therefore, this study has limited generalizability and should be interpreted as such.

\section{Recommendation}

Further studies are needed with larger sample size to explore difference in management of DM between family medicinebased care and endocrinology/hospital-based care and to explore other aspects like accessibility, convenience, and cost effectiveness.

\section{Acknowledgment}

The work was not supported or funded by any drug company.

\section{Disclosure}

The authors report no conflicts of interest in this work.

\section{References}

1. Masharani U, German MS. Pancreatic hormones and diabetes mellitus. In: Gardner DG, Shoback D, editors. Gardner Greenspan's Basic and Clinical Endocrinology. 9th ed. New York: McGraw-Hill Medical; 2011, Chapter 17.

2. International Diabetes Federation. IDF Diabetes Atlas. 5th ed. Brussels, Belgium: International Diabetes Federation; 2011. 
3. Alqurashi KA, Aljabri KS, Bokhari SA. Prevalence of diabetes mellitus in a Saudi community. Ann Saudi Med. 2011;31(1):19-23.

4. Leinung MD, Gianoukakis AG, Lee DW, Jeronis SL, Desemone J. Comparison of diabetes care provided by an endocrinology clinic and a primary-care clinic. Endocr Pract. 2000;6(5):361-366.

5. Aria K, Hirao K, Matsuba I, et al. The status of glycemic control by general practitioners and specialists for diabetes in Japan: a crosssectional survey of 15,652 patients with diabetes mellitus. Diabetes Res Clin Pract. 2009;83:397-401.

6. Spann SJ, Nutting PA, Galliher JM, et al. Management of type 2 diabetes in the primary care setting: a practice-based research network study. Ann Fam Med. 2006;4(1):23-31.

7. Ohman-Strickland PA, Orzano AJ, Hudson SV, et al. Quality of diabetes care in family medicine practices: influence of nurse-practitioners and physician's assistants. Ann Fam Med. 2008;6(1):14-22.

8. Ismail K, Winkley K, Rabe-Hesketh S. Systematic review and metaanalysis of randomised controlled trials of psychological interventions to improve glycaemic control in patients with type 2 diabetes. Lancet. 2004;363(9421):1589-1597.

9. Albalawi Y, Hussein SA, Khalid A. Comparison of diabetes control among type 2 diabetes mellitus patients treated in the primary health care clinics and diabetes center in King Saud University Hospitals. Am J Res Commun. 2014:2(11):1-27.

10. Ho M, Marger M, Beart J, Yip I, Shekelle P. Is the quality of diabetes care better in a diabetes clinic or in a general medicine clinic? Diabetes Care. 1997;20:472-475. Available from: http://care.diabetesjournals. org/content/20/4/472. Accessed 1 June, 2013.

11. Griffin S, Greenhalgh T. Diabetes care in general practice: meta-analysis of randomised control trials Commentary: Meta-analysis is a blunt and potentially misleading instrument for analysing models of service delivery. BMJ. 1998:390-396.
12. Ismail H, Wright J, Rhodes P, Scally A. Quality of care in diabetic patients attending routine primary care clinics compared with those attending GP specialist clinics. Diabet Med. 2006;23(8):851-856.

13. Al-Elq AH. Current practice in the management of patients with type 2 diabetes mellitus in Saudi Arabia. Saudi Med J. 2009;30(12): $1551-1556$.

14. de Pablos-Velasco P, Parhofer KG, Bradley C, et al. Current level of glycaemic control and its associated factors in patients with type 2 diabetes across Europe: data from the PANORAMA study. Clin Endocrinol. 2014;80(1):47-56.

15. Alvarez Guisasola F, Mavros P, Nocea G, Alemao E, Alexander CM, Yin D. Glycaemic control among patients with type 2 diabetes mellitus in seven European countries: findings from the Real-Life Effectiveness and Care Patterns of Diabetes Management (RECAP-DM). study. Diabetes Obes Metab. 2008;10 Suppl 1:8-15.

16. Daher AM, AlMashoor SA, Winn T. Glycaemic control and quality of life among ethnically diverse Malaysian diabetic patients. Qual Life Res. 2014;24(4):1-8.

17. Fox KM, Gerber Pharmd RA, Bolinder B, Chen J, Kumar S. Prevalence of inadequate glycemic control among patients with type 2 diabetes in the United Kingdom general practice research database: a series of retrospective analyses of data from 1998 through 2002. Clin Ther. 2006;28(3):388-395.

18. Scottish Study Group for the Care of the Young Diabetic. Factors influencing glycemic control in young people with type 1 diabetes in Scotland: a population-based study (DIABAUD2). Diabetes Care. 2001;24(2):239-244.

19. Shani M, Taylor TR, Vinker S, et al. Characteristics of diabetics with poor glycemic control who achieve good control. JAm Board Fam Med. 2008; 21(6):490-496.

20. Al-Hussein, FA. Diabetes control in a primary care setting: a retrospective study of 651 patients. Ann Saudi Med. 2007;28(4):267-271.

\section{Publish your work in this journal}

Diabetes, Metabolic Syndrome and Obesity: Targets and Therapy is an international, peer-reviewed open-access journal committed to the rapid publication of the latest laboratory and clinical findings in the fields of diabetes, metabolic syndrome and obesity research. Original research, review, case reports, hypothesis formation, expert opinion and commentaries are all considered for publication. The manuscript management system is completely online and includes a very quick and fair peer-review system, which is all easy to use. Visit $\mathrm{http}: / /$ www.dovepress.com/testimonials.php to read real quotes from published authors. 